\title{
A New Appliance for Improving the Miniscrew Stability
}

\author{
Nurhat Ozkalayci ${ }^{1}$ and Mehmet Yetmez $^{2}$ \\ ${ }^{1}$ Department of Orthodontics, Faculty of Dentistry, Bulent Ecevit University, 67100 Zonguldak, Turkey \\ ${ }^{2}$ Department of Mechanical Engineering, Faculty of Engineering, Bulent Ecevit University, 67100 Zonguldak, Turkey
}

Correspondence should be addressed to Mehmet Yetmez; yetmez@beun.edu.tr

Received 17 March 2016; Accepted 2 July 2016

Academic Editor: Moustafa N. Aboushelib

Copyright (C) 2016 N. Ozkalayci and M. Yetmez. This is an open access article distributed under the Creative Commons Attribution License, which permits unrestricted use, distribution, and reproduction in any medium, provided the original work is properly cited.

\begin{abstract}
The aim of this study is to present a new appliance called stability leg designed as an additional anchorage providing device for increasing primary stability of orthodontic miniscrew. For this purpose, two finite element models (FEMs) with two different cortical layer thicknesses of $1 \mathrm{~mm}$ and $2 \mathrm{~mm}$ are considered. In order to achieve the stability analysis, these two main models, namely, Model I and Model II, are divided into subgroups according to stability leg lengths. Two types of forces are considered. (1) First force is a constant force of $1 \mathrm{~N}$ which is applied to all two models. (2) Second force is defined in the range of 1-4 N. Each of 1, 2.5 , and $4 \mathrm{~N}$ of the second force is applied with a position angle ranging from $34^{\circ}$ to $44^{\circ}$. Results show that stability of a miniscrew with $5 \mathrm{~mm}$ leg increases primary stability of the miniscrew.
\end{abstract}

\section{Introduction}

The anchorage is one of the most important subjects of orthodontics [1]. Mainly, it can be classified as extraoral and intraoral. Extraoral anchorage can be provided with extraoral appliances. Actually, aesthetic is probably major difficulty about extraoral appliances. Internal anchorage can be divided into two groups as intramaxillary and intermaxillary. Dental implant researches mainly focus on dimensions and design of miniscrew or patient related factors such as bone quality and insertion area. Until now, different appliances, mechanics, elastics, wire bends, and so forth, have been designed. Result of a successful orthodontic treatment can be obtained by providing effective anchorage control [2-8].

Temporary anchorage devices (TADs) as miniscrews are used in modern orthodontic treatment mechanics. In spite of their stability problems, miniscrews can provide enough anchorage $[9,10]$. Once they lost their stability, it is difficult to reinsert them into the same location and this situation causes an ineffective solution. Particularly, different studies have been presented to improve the stability of the miniscrews focusing on the shape/size of miniscrews, quality of alveolar bone, or insertion site of the implant [11-13].

General purpose finite element code has been used at different studies of the orthodontic treatment mechanics [14].
It is a proper way to compute the stability of orthodontic miniscrews. For the computational analysis, a finite element model represents the human jaws approximately. Cortical layer thickness of the model is chosen between 1 and $2 \mathrm{~mm}$ in many finite element studies [15]. Generally, it is obvious for such studies that maximum load range is between 1 and $2 \mathrm{~N}$ [16]. Also, critical clinical angle range is assumed to be from $34^{\circ}$ to $44^{\circ}$ for the force application. This range is chosen in order to simulate intermaxillary Class II and Class III elastic usage. These conditions of loading and position are very important for a miniscrew stability which is controlled under both of intermaxillary and intramaxillary force load conditions [17-20]. Therefore, it is clearly seen that stability loss is major disadvantage of miniscrews.

In this study, a new appliance which is called stability leg is proposed as an additional anchorage creating device for increasing primary stability of miniscrew.

\section{Materials and Method}

In order to predict the fields of stress and displacement of a miniscrew stability, two different finite element models (FEMs) with two different cortical layer thicknesses are considered by using a general purpose finite element code ANSYS [21]. Each of the two FEMs is in $10 \mathrm{~mm} \times 10 \mathrm{~mm} \times$ 


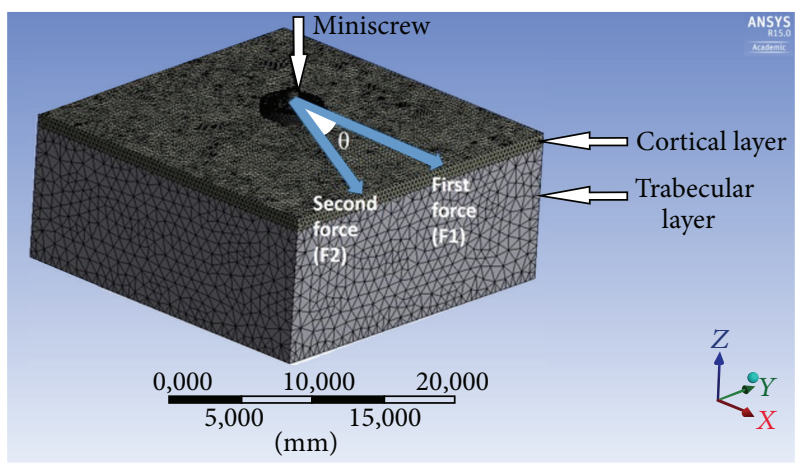

(a)

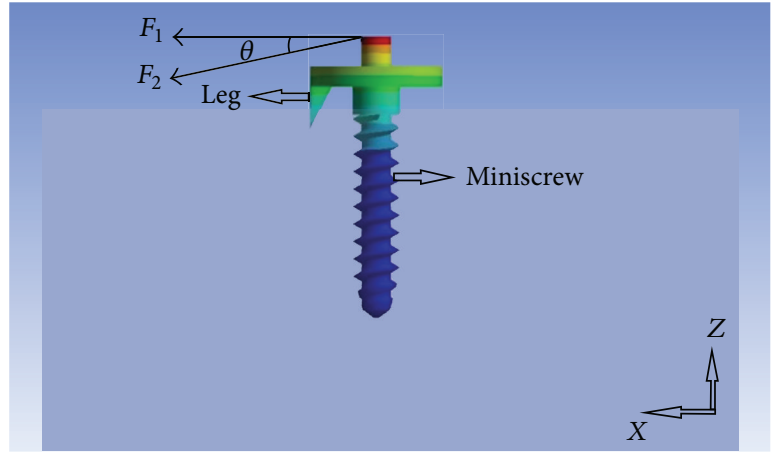

(b)

FIGURE 1: (a) FEM for miniscrew stability. (b) Force positions for the stability analysis.
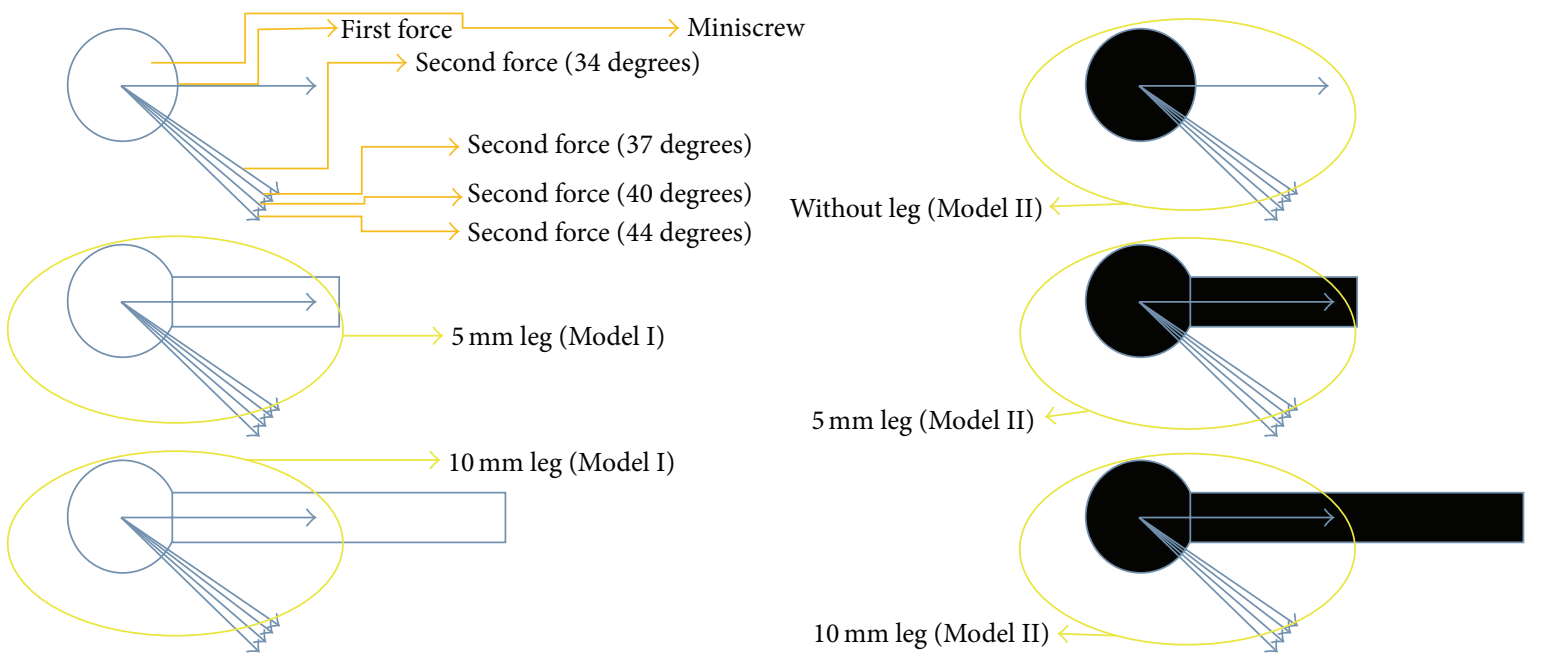

FIGURE 2: Representation of leg length and applied forces with a position angle ranging from $34^{\circ}$ to $44^{\circ}$.

$10 \mathrm{~mm}$ volume. While first FEM, namely, Model I, possesses a cortical layer of $1 \mathrm{~mm}$ in thickness, second FEM as Model II does a cortical layer of $2 \mathrm{~mm}$ in thickness, because the miniscrew's primer stability strongly depends on cortical bone strength [14]. Mechanical properties of the cortical layer are as follows: Young's Modulus $=13.7 \mathrm{GPa}$, Poisson's ratio $=0.3$, and density $=1.8 \mathrm{~g} / \mathrm{cm}^{3}$. Additionally, mechanical properties of the trabecular layer are as follows: Young's Modulus $=0.3 \mathrm{GPa}$, Poisson's ratio $=0.3$, and density $=0.8 \mathrm{~g} / \mathrm{cm}^{3}$. Miniscrew with $1.6 \mathrm{~mm}$ in width and $8 \mathrm{~mm}$ in length is Grade IV titanium alloy (Young's Modulus $=110 \mathrm{GPa}$, Poisson's ratio $=0.3$, and density: $4.5 \mathrm{~g} / \mathrm{cm}^{3}$ ) which is used for the FEMs including inserting the $8 \mathrm{~mm}$ screw along the bone. Both a higher order three-dimensional 20-node solid element (SOLID 186) and a three-dimensional 10-node tetrahedral structural solid element (SOLID 187) are used for the FEMs. In the analyses, while Model I includes 191024 elements, Model II possesses 315249 elements. The general representation of the FEMs is given in Figure 1(a).

In this analysis, a constant force (first force, $F_{1}$ ) of $1 \mathrm{~N}$ is applied to all two models. And second force $(1,2.5$, or $4 \mathrm{~N}$ as $F_{2}$ ) is applied to the models with respect to the critical clinical angle ranging from $34^{\circ}$ to $44^{\circ}$. The critical value of the second force is $4 \mathrm{~N}$, because, clinically, when the second force level exceeds $1 \mathrm{~N}$, dimensions of miniscrew become a significant factor for the primer stability of miniscrew [22]. All loading cases are applied to the tip of the screw through $x$ direction (see Figure 1(b)). Consequently, numerical analysis on stability of a miniscrew is completed at different boundary conditions. Actually, there are two critical regions in the analysis: (i) force contact region (FCR) and (ii) surface contact region (SCR).

Each of the two FEMs is divided into three subgroups: screw with $0 \mathrm{~mm}$ leg (without a leg), screw with $5 \mathrm{~mm}$ leg, and screw with $10 \mathrm{~mm}$ leg presented in Figure 2. For all subgroups, stress distribution and tip displacement of the miniscrew are computed by taking FCR and SCR into account.

\section{Results and Discussion}

Due to the clinical importance, results of stress and displacement distributions of FCR and SCR are given in $x$ - and $z$ direction. On one hand, results of FCR for Model I and Model II under constant position angle of $34^{\circ}$ are given in Figures 


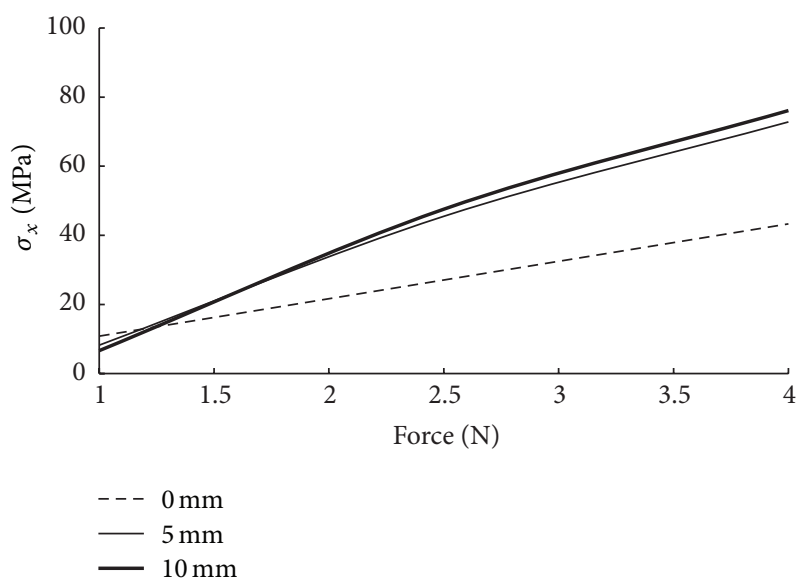

FIGURE 3: Variation of stress at $x$-direction for FCR of Model I under the position angle of $34^{\circ}$.

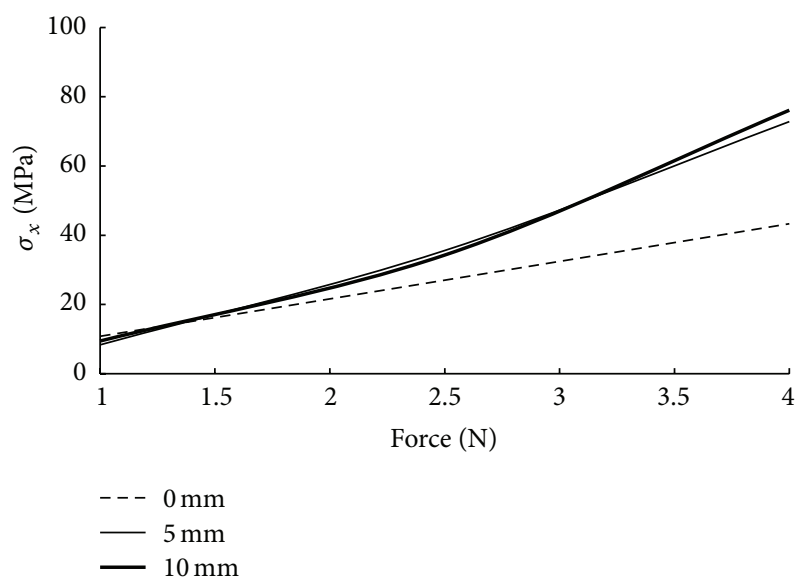

Figure 4: Variation of stress at $x$-direction for FCR of Model II under the position angle of $34^{\circ}$.

3-6. Figures 3 and 4 say that while Model I shows a concave stress distribution, Model II does a convex one. That means that increasing applied force increases stress gradient quickly.

Similarly, Figures 5 and 6 give that (a) displacement field at $x$-direction of a miniscrew with $5 \mathrm{~mm}$ leg is more useful than the others, (b) while Model I has a linear translation behavior and Model II still possesses a convex behavior. Corresponding to Figures 4 and 6, one can conclude that, over the applied force of $1.25 \mathrm{~N}$, stability of the miniscrew is questionable for Model II. However, Figures 3 and 5 clarify that the miniscrew with $5 \mathrm{~mm}$ leg of Model I is more suitable for the stability up to the load of $1.25 \mathrm{~N}$.

On the other hand, results of SCR of Model I and Model II under the angle of $34^{\circ}$ are given in Figures 7 and 8 . These two figures introduce that stress field at the horizontal direction $x$ of a miniscrew with $10 \mathrm{~mm}$ leg is in convex behavior for both Model I and Model II. However, stress field of the other two types ( $0 \mathrm{~mm}$ leg and $5 \mathrm{~mm} \mathrm{leg}$ ) varies linearly. In the stability point of view, a miniscrew with $5 \mathrm{~mm}$ leg is preferred for both

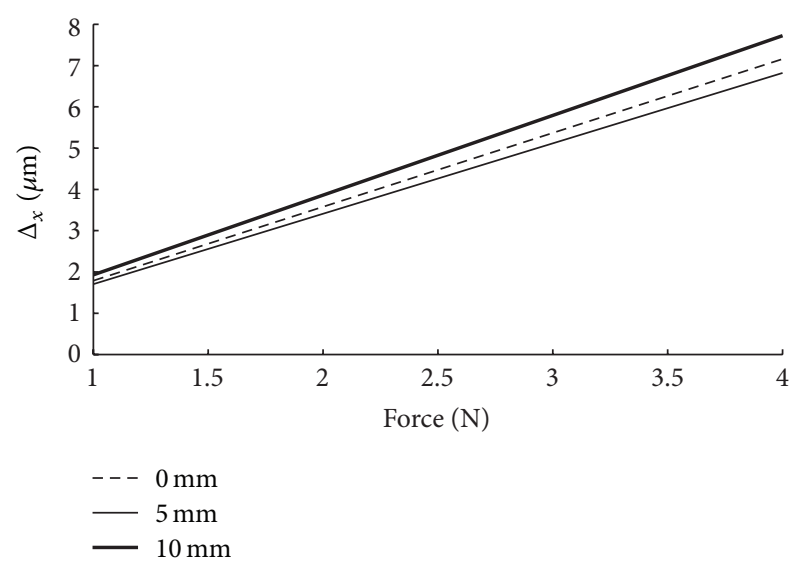

FIgURE 5: Variation of displacement at $x$-direction for FCR of Model I under the position angle of $34^{\circ}$.

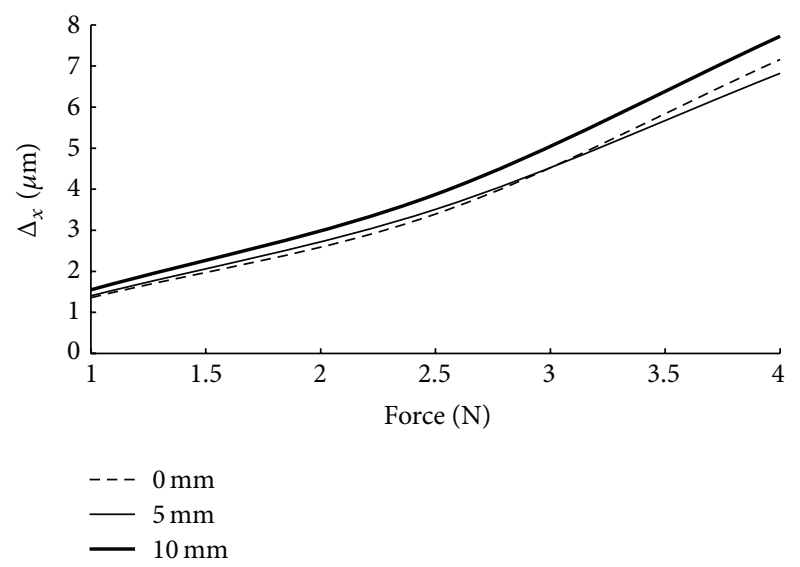

FIgURE 6: Variation of displacement at $x$-direction for FCR of Model II under the position angle of $34^{\circ}$.

models because of decreasing stress field around the contact region.

Finally, in order to figure the difference among the three screw types out, variation of position angle under the maximum force of $4 \mathrm{~N}$ in $z$-direction is also considered and results of FCR for Model I and Model II are presented in Figures 9-12.

Figure 9 shows that, due to the cortical bone thickness, a miniscrew with $10 \mathrm{~mm}$ leg does not improve its stability. However, a miniscrew with $5 \mathrm{~mm}$ leg is still suitable for the clinical applications according to the screw tip displacement of Model I given in Figure 11.

Figures 10 and 12 conclude that all types of stability leg display similar stability behavior for Model II and the lowest similarity is provided from $10 \mathrm{~mm}$ stability leg. This result can be seen due to the moment effect of the force system.

Besides, Table 1 is given as three-dimensional mean stress levels of the models with their standard deviations in the range of position angle $34-44^{\circ}$. Values of the mean stresses 


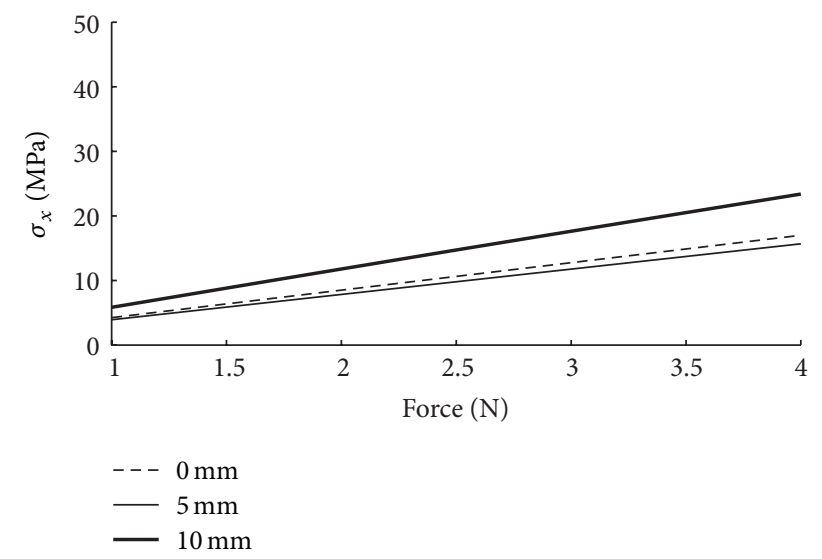

FIGURE 7: Variation of stress at $x$-direction for SCR of Model I under the position angle of $34^{\circ}$.

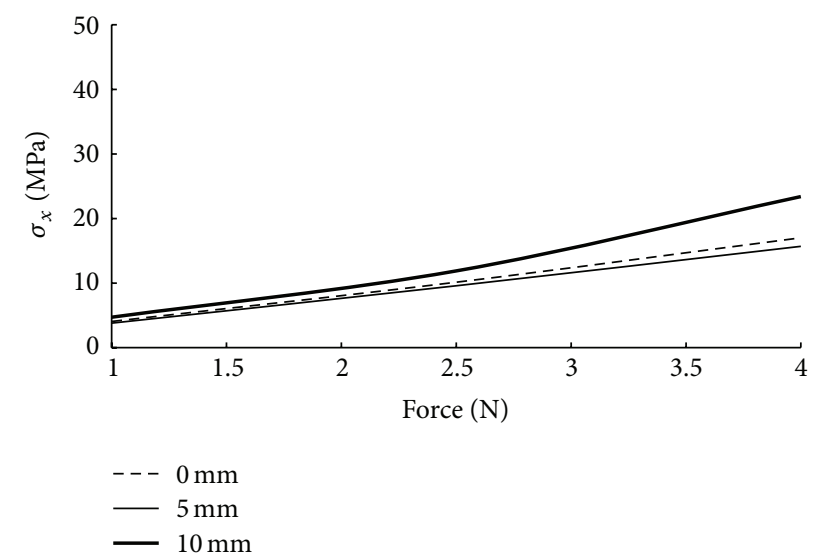

FIGURE 8: Variation of stress at $x$-direction for SCR of Model II under the position angle of $34^{\circ}$.

indicate that a miniscrew with $5 \mathrm{~mm}$ leg is superior to the other two configurations in all directions.

\section{Conclusion}

In order to determine which stability leg of the miniscrew is more suitable for stress or displacement field, finite element analysis is very powerful tool due to the geometrical, material, and loading difficulties of biomechanical investigations. This study concludes that (i) clinical application of stability leg is useful for not only increasing primary stability of miniscrews, but also decreasing the failure rate of miniscrews, (ii) a miniscrew with $5 \mathrm{~mm}$ leg is superior to the other two configurations, (iii) the results of the proposed FEMs are significantly acceptable for the sake of experimental/clinical conditions, and (iv) this type of investigation is an open area and more studies on this issue are needed, that is, new solid miniscrew with a leg design to improve the clinical studies or new porous miniscrew design with a leg to improve the biocompatibility.

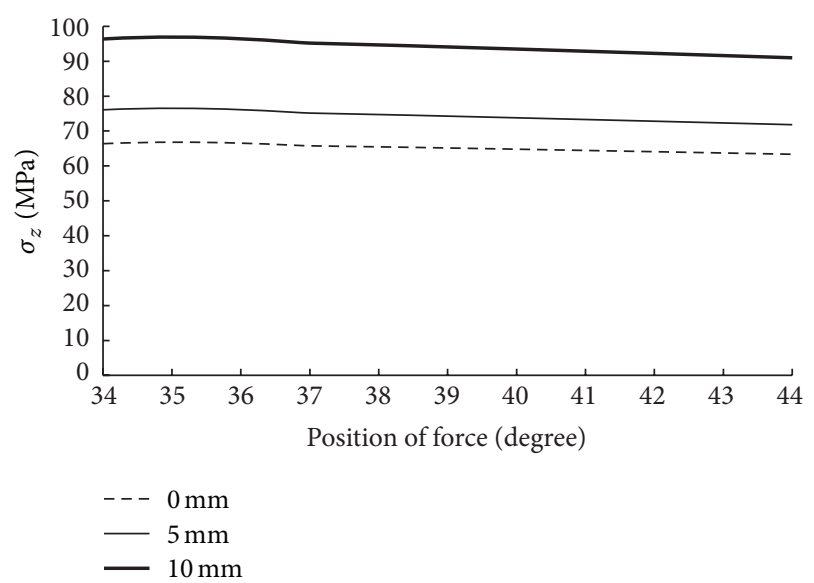

FIGURE 9: Variation of stress at $z$-direction for FCR of Model I under $4 \mathrm{~N}$.

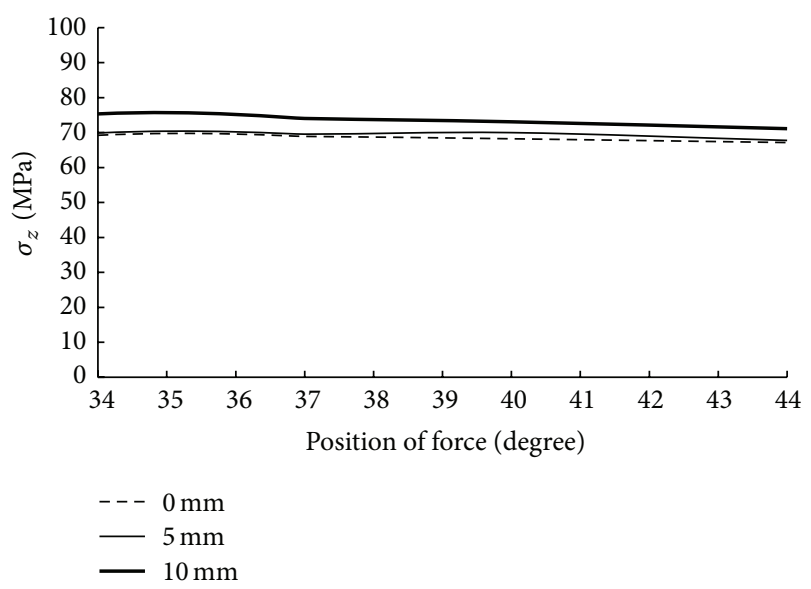

FIGURE 10: Variation of stress at $z$-direction for FCR of Model II under $4 \mathrm{~N}$.

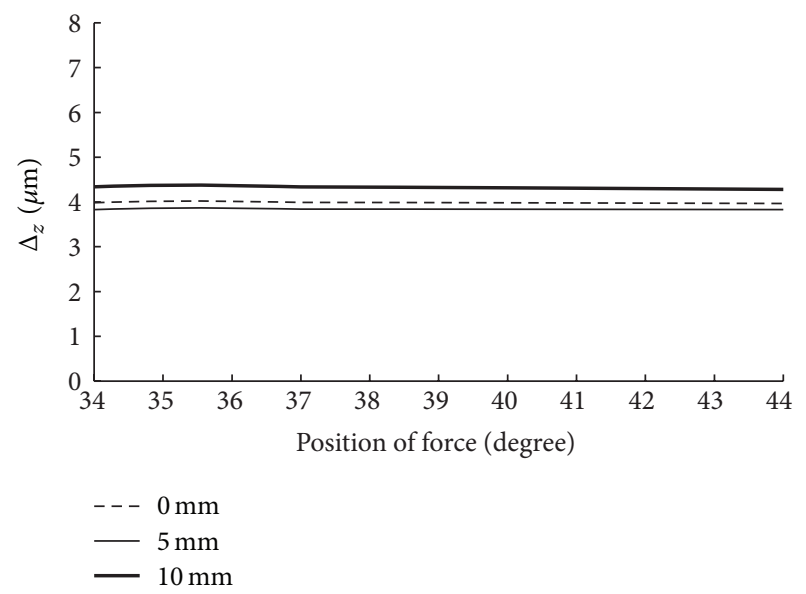

FIgURE 11: Variation of displacement at $z$-direction for FCR of Model I under $4 \mathrm{~N}$. 


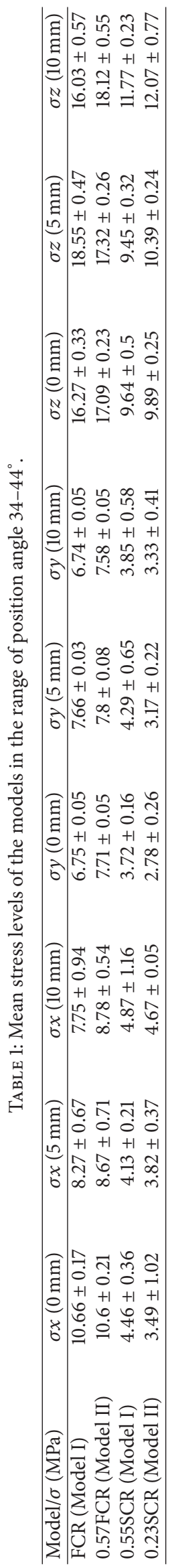




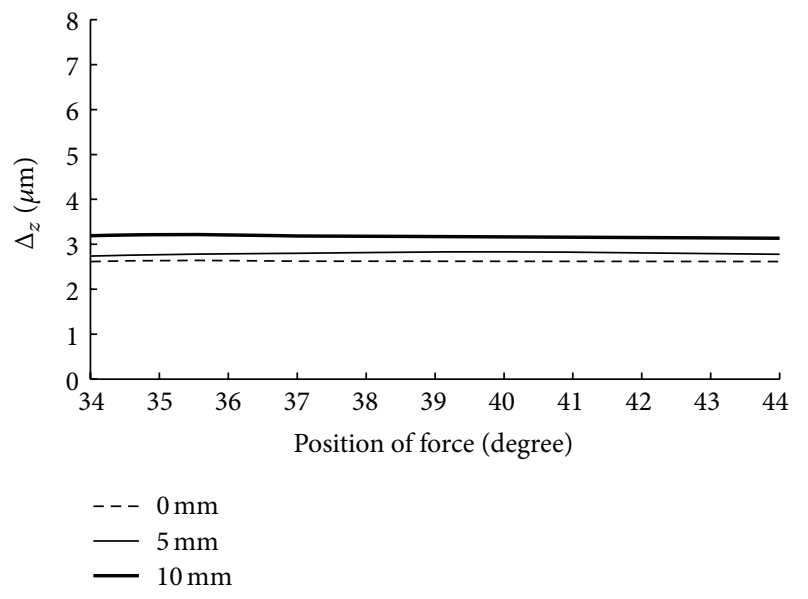

FIGURE 12: Variation of displacement at $z$-direction for FCR of Model II under $4 \mathrm{~N}$.

\section{Competing Interests}

The authors declare that they have no competing interests.

\section{References}

[1] A. Costa, M. Raffainl, and B. Melsen, "Miniscrews as orthodontic anchorage: a preliminary report," The International Journal of Adult Orthodontics and Orthognathic Surgery, vol. 13, no. 3, pp. 201-209, 1998.

[2] M. Nienkemper, J. Handschel, and D. Drescher, "Systematic review of mini-implant displacement under orthodontic loading," International Journal of Oral Science, vol. 6, no. 1, pp. 1-6, 2014.

[3] C.-Y. Pan, S.-T. Chou, Y.-C. Tseng et al., "Influence of different implant materials on the primary stability of orthodontic miniimplants," Kaohsiung Journal of Medical Sciences, vol. 28, no. 12, pp. 673-678, 2012.

[4] S. Hoste, M. Vercruyssen, M. Quirynen, and G. Willems, "Risk factors and indications of orthodontic temporary anchorage devices: a literature review," Australian Orthodontic Journal, vol. 24, no. 2, pp. 140-148, 2008.

[5] R. A. Meursinge Reynders, L. Ronchi, L. Ladu, F. van EttenJamaludin, and S. Bipat, "Insertion torque and success of orthodontic mini-implants: a systematic review," American Journal of Orthodontics and Dentofacial Orthopedics, vol. 142, no. 5, pp. 596-614, 2012.

[6] Y.-G. Kang, J.-Y. Kim, Y.-J. Lee, K.-R. Chung, and Y.-G. Park, "Stability of mini-screws invading the dental roots and their impact on the paradental tissues in beagles," The Angle Orthodontist, vol. 79, no. 2, pp. 248-255, 2009.

[7] Y. Er and E. Unsaldi, "The production of nickel-chromiummolybdenum alloy with open pore structure as an implant and the investigation of its biocompatibility in vivo," Advances in Materials Science and Engineering, vol. 2013, Article ID 568479, 7 pages, 2013.

[8] J. B. Cope, "Temporary anchorage devices in orthodontics: a paradigm shift," Seminars in Orthodontics, vol. 11, no. 1, pp. 3-9, 2005.

[9] T.-S. Lin, F.-D. Tsai, C.-Y. Chen, and L.-W. Lin, "Factorial analysis of variables affecting bone stress adjacent to the orthodontic anchorage mini-implant with finite element analysis," American Journal of Orthodontics and Dentofacial Orthopedics, vol. 143, no. 2, pp. 182-189, 2013.

[10] S. Singh, S. Mogra, V. S. Shetty, S. Shetty, and P. Philip, "Three-dimensional finite element analysis of strength, stability, and stress distribution in orthodontic anchorage: a conical, self-drilling miniscrew implant system," American Journal of Orthodontics and Dentofacial Orthopedics, vol. 141, no. 3, pp. 327-336, 2012.

[11] Y.-Y. Song, J.-Y. Cha, and C.-J. Hwang, "Mechanical characteristics of various orthodontic mini-screws in relation to artificial cortical bone thickness," The Angle Orthodontist, vol. 77, no. 6, pp. 979-985, 2007.

[12] M. Motoyoshi, T. Yoshida, A. Ono, and N. Shimizu, "Effect of cortical bone thickness and implant placement torque on stability of orthodontic mini-implants," International Journal of Oral and Maxillofacial Implants, vol. 22, no. 5, pp. 779-784, 2007.

[13] J. W. Lim, W. S. Kim, I. K. Kim, C. Y. Son, and H. I. Byun, "Three dimensional finite element method for stress distribution on the length and diameter of orthodontic miniscrew and cortical bone thickness," Korean Journal of Orthodontics, vol. 33, pp. 1120, 2003.

[14] V. Marimuthu, K. Kumar, N. Sadhasivam, R. Arasappan, A. Jayamurugan, and R. Rathinasamy, "Finite element analysis of stress and displacement around mini-implant using different insertion angles and various direction of orthodontic force in maxilla and mandible," Journal of Indian Orthodontic Society, vol. 49, no. 2, pp. 61-66, 2015.

[15] H.-J. Jang, S.-Y. Kwon, S.-H. Kim, Y.-G. Park, and S.-J. Kime, "Effects of washer on the stress distribution of mini-implant A finite element analysis," The Angle Orthodontist, vol. 82, no. 1, pp. 137-144, 2012.

[16] S. Yano, M. Motoyoshi, M. Uemura, A. Ono, and N. Shimizu, "Tapered orthodontic miniscrews induce bone-screw cohesion following immediate loading," European Journal of Orthodontics, vol. 28, no. 6, pp. 541-546, 2006.

[17] E. Stahl, L. Keilig, I. Abdelgader, A. Jäger, and C. Bourauel, "Numerical analyses of biomechanical behavior of various orthodontic anchorage implants," Journal of Orofacial Orthopedics, vol. 70, no. 2, pp. 115-127, 2009.

[18] M. Motoyoshi, S. Yano, T. Tsuruoka, and N. Shimizu, "Biomechanical effect of abutment on stability of orthodontic miniimplant: a finite element analysis," Clinical Oral Implants Research, vol. 16, no. 4, pp. 480-485, 2005.

[19] S.-J. Sung, G.-W. Jang, Y.-S. Chun, and Y.-S. Moon, "Effective en-masse retraction design with orthodontic mini-implant anchorage: a finite element analysis," American Journal of Orthodontics and Dentofacial Orthopedics, vol. 137, no. 5, pp. 648-657, 2010.

[20] Y.-J. Chen, H.-H. Chang, C.-Y. Huang, H.-C. Hung, E. H.-H. Lai, and C.-C. J. Yao, "A retrospective analysis of the failure rate of three different orthodontic skeletal anchorage systems," Clinical Oral Implants Research, vol. 18, no. 6, pp. 768-775, 2007.

[21] ANSYS $^{\circledR}$ Workbench $^{\mathrm{TM}}$ Version 15.0, 2014.

[22] A. Chatzigianni, L. Keilig, S. Reimann, T. Eliades, and C. Bourauel, "Effect of mini-implant length and diameter on primary stability under loading with two force levels," European Journal of Orthodontics, vol. 33, no. 4, pp. 381-387, 2011. 

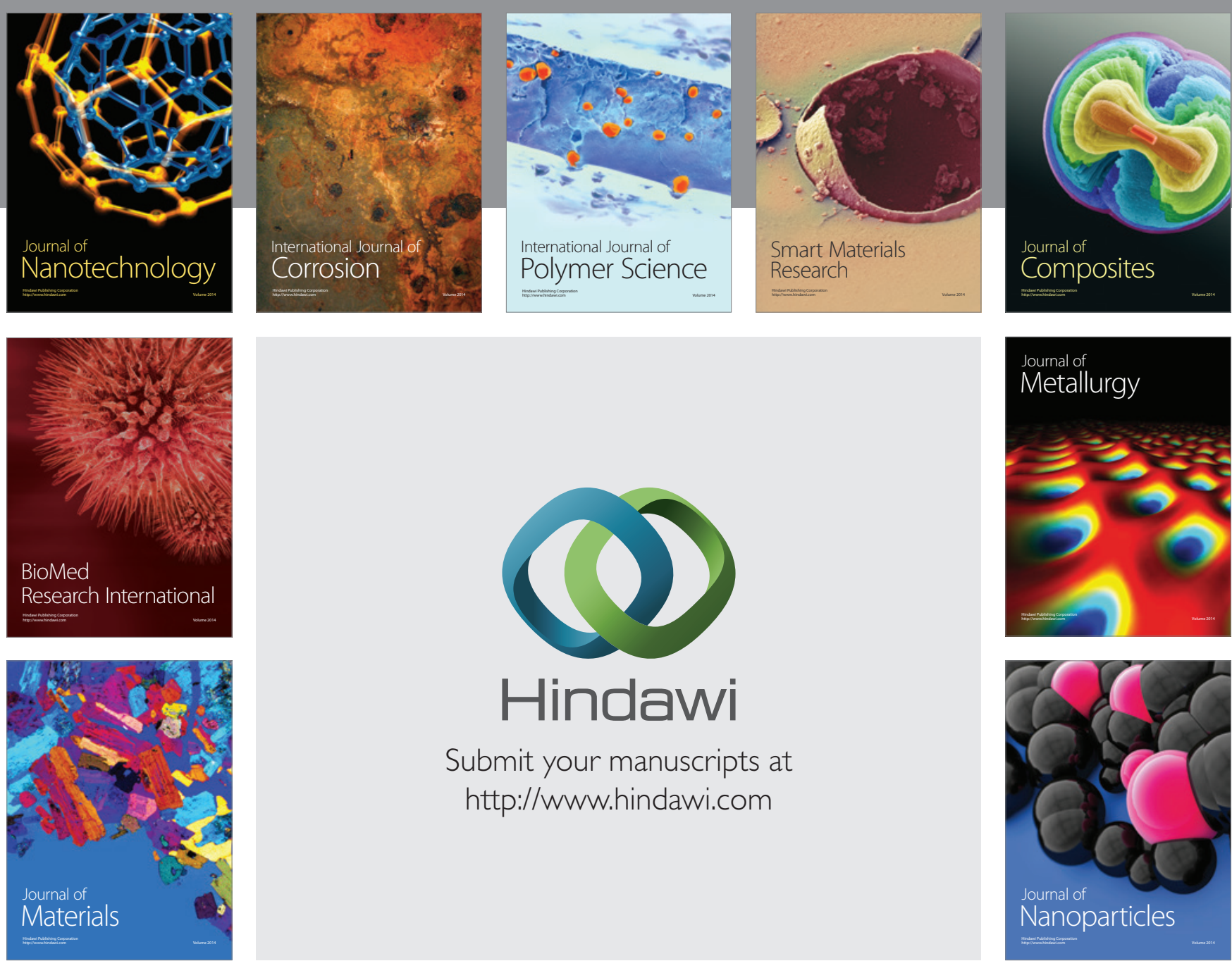

\section{Hindawi}

Submit your manuscripts at

http://www.hindawi.com

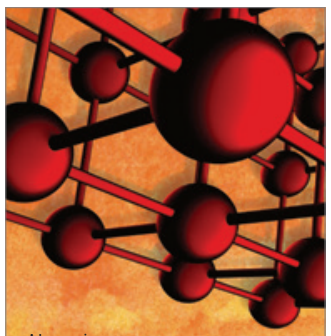

Materials Science and Engineering
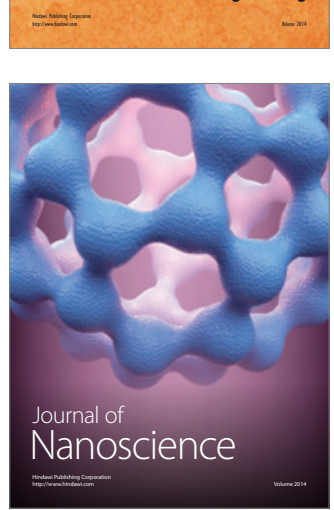
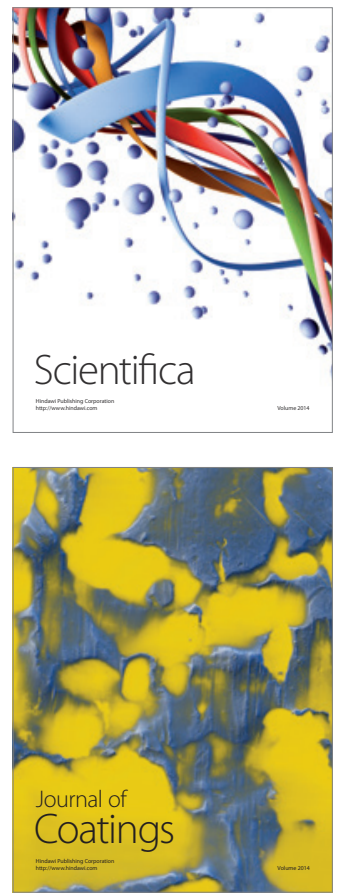
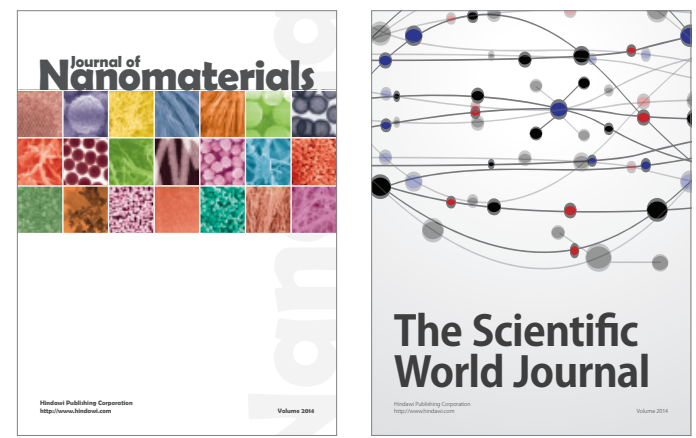

The Scientific World Journal
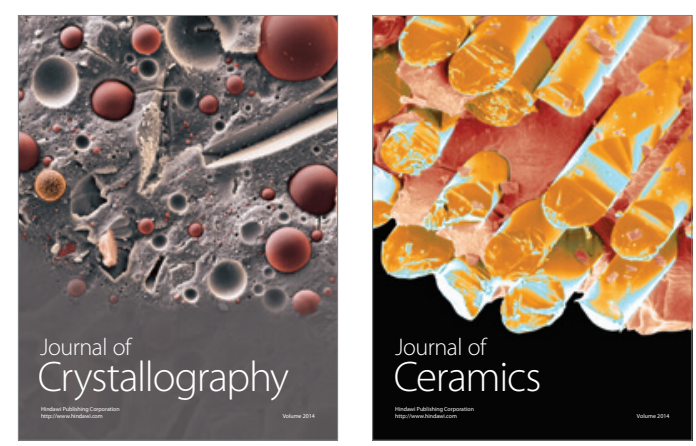
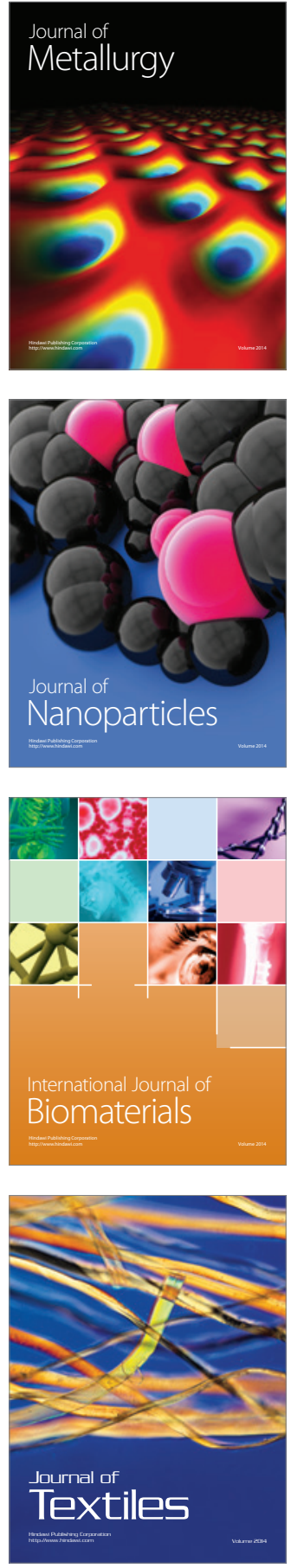